\title{
O MOVIMENTO ESCOLA SEM PARTIDO: ASCENSÃO E DISCURSO
}

\author{
LORENA ISMAEL FERNANDES ${ }^{1}$ \\ CAMILA ALVES FERREIRA ${ }^{2}$
}

\begin{abstract}
Resumo: Criado em 2004, o Escola Sem Partido ganhou notoriedade política no ano de 2014 por um projeto de lei federal. Os defensores do movimento atuam, principalmente, por meio da associação informal de pais, estudantes e professores que estão preocupados com a "contaminação" político-ideológica nas escolas. O presente estudo busca identificar as bases de atuação e os elementos teóricos que caracterizam o Escola Sem Partido para, as sim, verificar como o discurso do movimento é efetivado no seu engajamento virtual. Com a apresentação teórica e uma breve análise de publicações e comentários de usuários no Facebook em sua página oficial, entende-se que há uma desqualificação do papel da escola e do educador, promovendo uma centralidade da figura familiar e desestimulando a pluralidade de ideias e de concepçôes pedagógicas - princípios promulgados pela Constituição Federal em 1988.
\end{abstract}

Palavras-chave: Escola Sem Partido; Discurso; Esfera Pública; Esfera Privada.

\section{INTRODUÇÃO}

O movimento político Escola Sem Partido (ESP) foi fundado em 2004 pelo procurador do Estado de São Paulo, Miguel Nagib, e ganhou notoriedade por meio do projeto de lei (PL) apresentado, no ano de 2014, pelo deputado federal Erivelton Santana. O PL 7180/2014 propõe uma alteração no artigo 3o da Lei de Diretrizes e Bases da Educação Nacional (LDB - Lei no 9.394/1996) ao incluir, no tocante aos princípios do ensino, um dispositivo que se refere ao respeito às convicçóes do aluno, de seus pais ou responsáveis, dando precedência aos valores de ordem familiar sobre a educação escolar nos aspectos relacionados à educa-

1 Graduada em Ciências e Humanidades e graduanda em Políticas Públicas e Relações Internacionais pela Universidade Federal do ABC.

lorena.ismael98@gmail.com

2 Graduanda em Ciências e Humanidades, Políticas Públicas e Relações Internacionais pela Universidade Federal do ABC.

camila.afr@hotmail.com 
ção moral, sexual e religiosa. Em 2016, no Senado Federal, foi apresentado o projeto de lei 193/2016, de autoria do senador Magno Pereira, que busca incluir na LDB o Programa Escola sem Partido (ESP).

De acordo com o criador do movimento, o surgimento do Escola Sem Partido foi uma reação ao fenômeno da instrumentalização do ensino para fins político-ideológicos, partidários e eleitorais (ESCOLA SEM PARTIDO, 2018a), baseado no reconhecimento de um processo denominado de "doutrinação ideológica” que, segundo o ESP, está ocorrendo nas escolas brasileiras. Este processo é caracterizado por uma relação professor-aluno de transmissão massiva de ideias e concepçôes particulares dos educadores para os estudantes, em que eles, como "audiência cativa", são influenciados e passam a ter uma visão de mundo distorcida, ferindo a liberdade individual de cada estudante e a autonomia familiar de educar a criança conforme seus princípios pessoais.

Para Nagib, também coordenador do movimento, o ESP atua em duas frentes distintas: a primeira mediante ao Programa Escola Sem Partido, que consiste em um anteprojeto de lei que obriga a afixação de cartazes com os "deveres do professor" em todas as salas de aula do ensino fundamental no país, e a segunda por meio da associação informal de estudan tes, pais e professores que estão preocupados com a "contaminação" político-ideológica das escolas (SANTANA, 2016). No início, a principal estratégia do movimento foi a judicialização da relação entre professores e alunos, tendo, posteriormente, passado a pressionar as assembleias estaduais e municipais por projetos de leis que incluíssem e legitimassem suas posiçôes, processo que está se intensificando (MACEDO, 2017).

As mídias sociais são o principal instrumento de divulgação e articulação entre os indivíduos que apoiam a causa e os ideais do ESP, sendo fator essencial na expansão do movimento. A página oficial no Facebook, criada em 2014, conta com mais de 238 mil seguidores ${ }^{3}$ e publica, majoritariamente, informações políticas sobre os projetos de lei do ESP em tramitação e denúncias, com fotos e vídeos de alunos e pais contra professores e escolas. Inclusive, um dos fatores centrais na mobilização virtual é a divulgação de testemunhos de alunos, visando a exposição “desses falsos educadores” na tentativa de frear essa “contaminação ideológica”, que

3 Acesso na página Escola Sem Partido em maio de 2020. Cabe ressaltar que, além da página oficial, existem outras páginas e diversos grupos, também no Facebook, com o mesmo nome e que mobilizam questôes similares nesses ambientes, com divulgação de "cenas de doutrinação", denúncias a escolas e reportagens com o andamento dos projetos de lei em cidades e estados. 
é a verdadeira face, segundo os defensores do movimento, de um discurso sustentado pelos professores de ganho da "autonomia crítica" dos alunos.

O presente estudo busca identificar as bases de atuação e os elementos teóricos que caracterizam o movimento, para assim compreender como o discurso do Escola Sem Partido é efetivado no seu engajamento virtual. A partir de uma análise realizada em 2018, após a realização da eleição presidencial que marcou a vitória de um candidato (Jair Bolsonaro) que defende esta agenda, busca-se observar também como os seguidores responderam ao processo eleitoral.

A primeira seção do texto apresenta uma exposição dos princípios e demandas do ESP a partir da perspectiva "público versus privado", isto é, da disputa na atribuição dos papéis do Estado e da família no processo de ensino. A seção seguinte discorre sobre o referencial teórico-metodológico selecionado para a realização da análise dos comentários virtuais dos seguidores do movimento. Por fim, a terceira seção apresenta a análise de publicações e comentários de usuários no Facebook a fim de verificar a aplicação dos elementos discursivos no ambiente virtual.

\section{ESCOLA SEM PARTIDO - LUTAS E CONTRADIÇÕES}

A pauta do Escola Sem Partido se constitui como uma das principais iniciativas da onda conservadora no Brasil que está afetando diversos países no mundo (DE MORAES, 2018). Segundo Botelho e Ferreira (2012), os valores comuns dos conservadores estão relacionados à importância atribuída à religião, a valorização das instituições intermediárias entre o Estado e os indivíduos (como família, corporação, entre outros) e, consequentemente, uma crítica à centralização estatal e ao individualismo moderno.

A linha argumentativa e princípios defendidos pelo movimento não é inédito. Durante a história brasileira é possível identificar ações voltadas à continuidade ou retomada de concepções educacionais conservadoras: na concepção de pedagogia tradicional (SAVIANI, 2010), que foi plenamente predominante até os anos 1940 e teve como um dos principais articuladores a Igreja Católica, a religião e a pedagogia estariam mutuamente ligadas e há uma priorização da família e da Igreja frente ao Estado - isto é, como o Estado se constitui por uma instituição de caráter positivo, ele deveria se subordinar às instituições naturais [famílias] e sobrenatural [Igreja]. 
Com a ação dos chamados renovadores educacionais, o desenvolvimento de ideias pedagógicas mais progressistas, surge uma concepção denominada Pedagogia Nova, proporcionando uma mudança de enfoque sobre qual é o papel da escola; o foco deixa de ser "o que deve ser ensinado", e se torna "como ensinar e para quem" (SAVIANI, 2010). A defesa da autonomia docente, da liberdade do aluno, da laicização do ensino e da democratização do acesso são os pilares da pedagogia nova, em que não há uma hierarquia nas funções da família, Igreja e Estado.

O Escola sem Partido representa um retorno de caráter funcional e sectário aos ideólogos brasileiros conservadores e ao positivismo do início do século XX (CIAVATTA, 2017). Para Nicolazzi (2016), um dos pontos mais controversos dos projetos de lei que derivam do movimento é o entendimento de que os professores não devem abordar conteúdos que possam contrariar as convicções morais da família do aluno. Isso acarretaria, por exemplo, à restrição de aprendizagem de conteúdos relevantes para a forma intelectual do estudante como o contato com a teoria evolucionista e o conhecimento de diferentes regimes de governo.

Sob esta perspectiva, uma das bases de defesa do movimento é a separação do espaço privado e público; transfere-se a responsabilidade da educação exclusivamente para a família, a quem caberia toda a formação moral e ética das crianças. O espaço público da escola teria como função somente a promoção do aprendizado referente aos conteúdos (MACEDO, 2017).

A Constituição Federal de 1988 afirma, em seu artigo 205, que "a educação, direito de todos e dever do Estado e da família, será promovida e incentivada com a colaboração da sociedade, visando ao pleno desenvolvimento da pessoa, seu preparo para o exercício da cidadania e sua qualificação para o trabalho" (BRASIL, 1988, p.160), contrapondo o que é defendido pelo movimento ao instituir um compartilhamento de responsabilidades entre os atores.

A atual grande ameaça para os defensores e simpatizantes do ESP é a chamada ideologia de gênero. Para Miguel (2016), porém, a agenda que propiciou notoriedade ao movimento foi o combate à doutrinação marxista, porém, a "captura" do debate sobre gênero fortaleceu o alcance do ESP, articulando os dois princípios para potencializar suas ações. O conceito de ideologia se apresenta, teoricamente, como um termo polissêmico e, no caso, refere-se a um conjunto de ideias características compartilhadas por um grupo (caracterizados como "marxistas", "comunistas" e qualquer denominação relacionada a um viés político à esquerda) que, associado à noção de gênero, tem como objetivo projetar uma naturalização de 
que "ninguém nasce homem ou mulher” e que a instituição familiar será destruída caso tal discurso se propague, sendo um instrumento de dominação dos professores para com a formação dos alunos.

Segundo Penna (2017, p. 09), o ESP age a partir de quatro elementos centrais: "primeiro, uma concepção de escolarização; segundo, uma desqualificação do professor; terceiro, estratégias discursivas fascistas; e, quarto, a defesa do poder total dos pais sobre os seus filhos".

Existe um consenso entre o movimento de que há um pensamento hegemônico “da esquerda” nas universidades e, assim, a própria formação dos professores é enviesada ideologicamente. Sob o aspecto da existência de uma hegemonia, é importante ressaltar que no Brasil, especialmente no ano de 2018, período em que a análise deste artigo foi realizada, o campo político estava em disputa - conflito no campo cultural e político - , abrindo margem para ascensão de grupos dispostos a instaurar, de fato, um discurso hegemônico.

Para Gramsci, a hegemonia representa uma dominação consentida, na qual as estruturas de poder e autoridade devem ser aceitas como legítimas e naturais, e não por meio da imposição da violência (ALVES, 2010). O Escola Sem Partido age na legitimação do movimento a partir de sua institucionalização com leis e normas, além de atuar próximo as massas, com a estratégia de denúncia dos professores, por exemplo, criando um bloco ideológico que permite a essa classe dirigente elaborar e preservar um monopólio intelectual (PORTELLI, 1977).

\subsection{A confusão entre público e privado}

Como apresentado, os apoiadores do movimento ESP defendem a separação das atribuições educacionais entre o espaço público (escola) e privado (família), sendo um papel familiar a discussão de tópicos considerados sensíveis. Para um maior entendimento teórico desta dimensão, busca-se discutir a dicotomia público/privado a partir dos estudos clássicos de Habermas (1984), Arendt (2007) e De Holanda (1995). A complexidade do assunto é reconhecida, logo, não é almejado o esgotamento do debate, mas sim, uma contextualização de ideias gerais que fundamentam a argumentação aqui proposta.

Dado o dinamismo dos conceitos de "esfera pública” e "esfera privada”, Habermas (1984) entende a necessidade de uma recuperação histórico-sociológica do termo "público", que adquiriu diversos significados ao longo do tempo. O autor aponta que, em sua origem, a noção de “público" estava associada ao âmbito da coletividade e a prática do poder (a 
sociedade dos iguais), a esfera privada, por sua vez, dizia respeito ao campo particular (sociedade dos desiguais). Mas, historicamente, nota-se mudanças nessas relações; a instauração do Estado-nação, por exemplo, vinculou a figura do Estado ao conceito de público. A partir do desenvolvimento econômico e social do século XIX, Habermas identifica o marco da "fusão" entre as fronteiras do público e privado, isto porque, os eventos ocorridos neste período, conduziram a uma constante intervenção estatal na sociedade e na esfera privada, tendo-o como “protetor" e "mediador de conflitos" (IGLESIAS, 2019).

Arendt (2007) adota igualmente uma abordagem histórica para a compreensão dos conceitos de público e privado. Em sua argumentação, e de forma sintetizada, o espaço público está relacionado ao exercício da vida política, que está relacionado em si a liberdade e a ação. $\mathrm{O}$ espaço privado envolve as necessidades para a sobrevivência, a manutenção da vida e dos interesses individuais. Embora haja uma distinção evidente entre os dois conceitos, existe uma complementação entre eles, pois não há espaço público (participação na vida política, o comum) sem a possibilidade de exercer a manutenção de sobrevivência e vice-versa (GONZAGA; DO COUTO, 2019).

Em sua obra Entre o passado e o futuro, Arendt (2011) aborda em um dos seus textos a questão da educação. Para a autora, a educação deve apresentar o "mundo comum" para a criança, tendo os pais, desta forma, a responsabilidade de proteção durante o processo. A família é a instituição central para o desenvolvimento da criança antes da sua inserção no espaço público. A escola, neste cenário, é o primeiro contato da criança com o mundo. Mas, Arendt ressalta que a escola não é o "mundo comum" por completo, mas sim, um local de proteção como o lar. Assim, o professor tem a mesma responsabilidade de apresentar o "espaço público" ao indivíduo. Em paralelo ao caso do Escola Sem Partido, há uma negação desta interpretação, já que se assume o protagonismo familiar na condução desta "proteção”, sendo a escola um ambiente "seguro" que não se opõe aos ensinamentos domésticos.

$\mathrm{Na}$ conjuntura brasileira, e já defrontando com os elementos identificados no movimento ESP de maneira mais crítica, torna-se necessário o resgate do termo "homem cordial”, cunhado por Sérgio Buarque de Holanda na obra Raízes do Brasil que expõe que as relaçôes construídas no âmbito público, inclusive a vida política, têm reflexos no âmbito privado, nas relaçóes pessoais, e na obra mencionada De Holanda afirma que:

O Estado não é uma ampliação do círculo familiar e, ainda menos, uma integração de certos agrupamentos, de certas vontades particularistas, de que a família é o melhor exemplo. Não existe, entre o círculo familiar e o Estado, uma gradação, mas antes uma descontinuidade e até uma oposição. A indistinção fundamental entre 
as duas formas é prejuízo romântico que teve os seus adeptos mais entusiastas do século dezenove. De acordo com esses doutrinadores, o Estado e as instituiçóes descenderiam em linha reta, e por simples evolução, da família. A verdade bem outra, é que pertencem a ordens diferentes em essência (HOLANDA, 1995, p.245).

De acordo com o PL 7180/2014 (e posteriormente, PL 193/2016), observou-se que o defendido pelo movimento ESP é a defesa da supremacia familiar sobre o público/Estado, o que é apontado para Sérgio Buarque de Holanda como prejuízo romântico do século XIX e é retomado hoje por entusiastas conservadores do século XXI. Em contrapartida, em um regime democrático como o atual regime brasileiro, as definições públicas devem se sobrepor ao cotidiano privado; um exemplo é a laicização estatal, fato consolidado via constituinte, sendo contraposto num projeto de lei que visa a sobreposição dos interesses religiosos familiares dentro do contexto do ensino público (e, por conseguinte laico).

Especificamente ao que concerne à educação, o autor é categórico, e ao projetar sua argumentação no objeto de estudo, entende-se que as intervenções do ESP na liberdade de ensino garantida via LDB são equivocadas, podendo prejudicar o desenvolvimento intelectual das crianças em vez de "defendê-las de doutrinação ideológica":

[...] a obediência, um dos princípios básicos da velha educação, só deve ser estimulada na medida em que possa permitir uma adoção razoável de opinióes e regras que a própria criança reconheça como formuladas por adultos que tenham experiência nos terrenos sociais que ela ingressa. "Em particular", acrescenta (defensores da pedagogia científica da atualidade), "a criança deve ser preparada para desobedecer nos pontos em que sejam falíveis as previsões dos pais (HOLANDA, 1995, p.249).

Ou seja, é desejável que a criança desenvolva senso crítico e não seja apenas tratada como ser de "audiência cativa". Em síntese, restringir a educação ao círculo familiar acrescida à censura do papel dos professores e pedagogos pode causar prejuízos no desenvolvimento infanto-juvenil; De Holanda (1995) aponta prejuízos extremos, mas antes de se chegar a tal ponto, outras debilidades podem ser ocasionadas.

\section{METODOLOGIA}

Com o objetivo de analisar os elementos discursivos do movimento no ambiente virtual, a metodologia empregada contará com a aplicação de uma técnica inspirada na análise 
do discurso ${ }^{4}$. Neste sentido, compreende-se que o discurso não é circunscrito somente à fala, mas considera o contexto em que os elementos discursivos e não discursivos estão inseridos (FOUCAULT, 1986). Os discursos são compostos por enunciados, que serão expostos aqui em forma de publicaçóes e interaçôes coletadas em uma rede social; os enunciados, isolados de seu contexto histórico, de seus sujeitos e campos de constituição e validade não delineiam em si práticas discursivas, o que somente é possível através da compreensão desses múltiplos componentes (FISCHER, 2001). Para Foucault (1986, p. 114), “[não há] enunciado livre, neutro e independente; mas sempre um enunciado fazendo parte de uma série ou de um conjunto (...)", em outras palavras, o sujeito e suas produções linguageiras devem ser percebidas por meio de um viés contextual e ideológico, não havendo neutralidade no seu uso (ORLANDI, 2005).

Assim, o recorte temporal foi realizado com base no período pré-eleitoral, datando o início de outubro de 2018, e no período pós-eleitoral, abrangendo um intervalo de 10 dias depois do segundo turno presidencial. Nos critérios de escolha das publicaçóes e comentários foram excluídas as publicações em forma de vídeo, sendo selecionados apenas conteúdo expresso em foto, texto ou reportagem; e os comentários selecionados são os que tiveram maior índice de reações dos demais usuários, opção estimulada pelo entendimento de que a reação representa, na maioria das vezes, a concordância com o texto escrito.

Outro aspecto importante trazido por Foucault (1986) em relação à construção de discursos é a interdiscursividade, ou seja, a heterogeneidade discursiva dentre adeptos e não adeptos a determinados enunciados, levando em consideração o dissenso e o campo de disputa em que estão inseridos discursos, inclusive apagamentos e esquecimentos (FISCHER, 2001, p.212). O movimento ESP é de cunho político e se articula fundamentalmente nas instâncias Legislativa e Executiva. Desta forma, analisar o seu comportamento em uma época eleitoral é relevante no sentido de que seus interesses e disputas estão “em jogo" através dos representantes que serão escolhidos.

\section{$4 \quad$ ANÁLISE DE RESULTADOS}

\footnotetext{
4 Cabe ressaltar que a análise do discurso é uma técnica muito refinada, que possui peculiaridades e exige um alto grau de conhecimento metodológico, logo, alerta-se para possíveis descompassos.
} 
A primeira publicação, coletada no dia 04 de novembro de 2018, foi postada no dia 04 de outubro do mesmo ano com um link de uma reportagem. A manchete informa que o "Colégio Santo Agostinho, do Rio, suspende uso de livro considerado 'comunista' por grupo de pais” (site O Globo); o comentário da página por sua vez, apresenta o texto:

COLÉGIO RECUA DEPOIS DE TENTAR IMPOR AOS ALUNOS A LEITURA DE LIVRO DE PROPAGANDA IDEOLÓGICA DISFARÇADA DE LITERATURA, PARABÉNS AOS PAIS POR DEFENDEREM SEUS FILHOS!

Falar em 'censura', como faz o Globo noutra reportagem, é pura desonestidade. $\mathrm{O}$ livro está à disposição para quem quiser ler. Inadmissível é tentar fazer a cabeça de crianças obrigando-as a ler uma obra de propaganda ideológica (ESCOLA SEM PARTIDO, 2018b).

A publicação conta com mais de 2.500 "reações” dos usuários da rede social e mais de 100 comentários, tendo a expressiva marca de 2.056 compartilhamentos. O livro em questão, Meninos sem pátria, retrata vida de uma família exilada na ditadura brasileira. O autor Luiz Puntel lançou a obra na década de 1980, inspirando-se "no drama da volta dos exilados, e não em uma apologia ao comunismo” (O GLOBO, 2018).

Observa-se, nesta situação, a tentativa de um esvaziamento histórico deste episódio: a ditadura militar. $\mathrm{O}$ controle que está sendo exercido sobre o que deve ser aprendido ou não nas escolas está relacionado, de certa forma, com uma ideia trabalhada por Michel Foucault (1979) de que o poder e o conhecimento são elementos essenciais como forma de controle social por meio das instituições. O Escola Sem Partido "ataca” a escola, principal instituição moderna de desenvolvimento intelectual do indivíduo, ainda que possua um regime disciplinar (FOUCAULT, 1979), para combater pensamentos e reflexões que não estão de acordo com suas crenças, limitando, consequentemente, a capacidade do indivíduo de conhecer perspectivas e realidades distintas, restringindo as noçôes de "pluralidade de ideias e concepções pedagógicas” defendidas na Constituição Federal de 1988, artigo 206 (BRASIL, 1988, p.160).

$\mathrm{O}$ jogo de palavras desqualifica o conteúdo presente na obra, transformando-a em uma ameaça às crianças que teriam acesso. Assim, os pais - que, possivelmente, não conhecem a obra -, acreditam na informação e compartilham a notícia na sua rede pessoal com a intenção de alertar outros pais. A defesa em relação a acusação de censura fortalece a argumentação no sentido de que, realmente, eles não estão buscando a proibição da comercialização do livro, mas sim, que as crianças sejam protegidas e que os pais possam escolher, indivi- 
dualmente, se devem ou não permitir que o filho leia a obra, sobrepondo o papel familiar sob a função da escola.

A segunda análise foi realizada dia 08 de outubro de 2018, e é referente a uma publicação da página oficial do ESP no Facebook, do dia 02 de outubro de 2018, período entre turnos eleitorais, e trata-se de declaração visual explícita de apoio a um dos candidatos presidenciais (Jair Bolsonaro) por parte de um professor em sala de aula. $\mathrm{Na}$ foto da publicação, o professor em questão está virado para a lousa, com uma camiseta camuflada com os dizeres “Melhor Jair se acostumando. Bolsonaro presidente 2019”. Elaboradas e repetidas pelo indivíduo que a publicou originalmente (não identificado pela página do ESP), estão as frases: "MELHOR JAIR SE ACOSTUMANDO” e "Gostei desse professor!”; ambas as frases possuem “Jair” em vez de “já ir”, norma-padrão da língua portuguesa, sendo uma alusão ao então candidato Jair Bolsonaro, lema que foi adotado por inúmeros seguidores do movimento no decorrer da campanha. A página, por sua vez, produz o seguinte texto, que acompanha a imagem descrita:

EXISTEM PROFESSORES DE DIREITA QUE USAM A SALA DE AULA PARA PROMOVER SUAS PRÓPRIAS REFERÊNCIAS IDEOLÓGICAS POLÍTICAS E PARTIDÁRIAS?

É claro que sim! É claro que está errado! Mas são franco-atiradores, trabalham por conta própria. No Brasil, quem promove a doutrinação político-ideológico em sala de aula, de forma sistemática e organizada, há mais de 30 anos, com apoio teórico (Gramsci, Althusser, Freire, Saviani...), político (governos e partidos de esquerda, PT à frente). Burocrático (MEC e secretarias de educação), editorial (indústria do livro didático) e sindical é a esquerda.

Por fim, o candidato da direita apoiado pelo professor da foto, já se comprometeu publicamente a combater o uso das escolas e universidades para fins de propaganda ideológica, política e partidária, caso seja eleito; enquanto os candidatos da esquerda morrem de medo do Escola Sem Partido (ESCOLA SEM PARTIDO, 2018b).

$\mathrm{Na}$ análise do conteúdo, encontra-se uma confusão entre as noções de ideário e ideologia, isto tendo como referência o conceito de ideologia apresentado por Marilena Chauí (2008). Ao tratar os posicionamentos políticos à esquerda ou direita, a publicação denomina como "ideologias" quando, na verdade, os conjuntos sistemáticos de ideias apresentados por ambos os grupos são ideários. Apesar da discussão em torno do conceito de ideologia, observa-se, ao longo do tempo, que seu enfoque é associado de maneira mais incisiva as ideias das classes dominantes e, assim, a dominação e a exploração dos detentores do capital. Para a 
autora, a ideologia é um conjunto de ações consolidada no decorrer da história humana para a manutenção de relações de dominação e poder. Nas palavras dela:

\footnotetext{
Nossa ideia aqui será desfazer a suposição de que ideologia é um ideário qualquer ou qualquer conjunto encadeado de ideias e, ao contrário, mostrar que a ideologia é um ideário histórico, social e político que oculta a realidade, e que esse ocultamento é uma forma de assegurar e manter a exploração econômica, a desigualdade social e a dominação política (CHAUÍ, 2005, p.07).
}

Em outras palavras, constata-se que a existência de um ideário é necessária a cada grupo, pois é isso que caracteriza seus princípios e suas ações. Quando educadores defendem o senso crítico e a liberdade de ensino, por exemplo, são traços que compóem seu ideário. Não há um desejo de "ocultar a realidade" para "assegurar e manter a exploração econômica”. A partir do momento em que os participantes do ESP atribuem o termo "ideologia" quase que exclusivamente aos grupos de esquerda, há uma desqualificação dos ideários destes indivíduos, considerando-os maléficos e perigosos.

Ademais, a publicação considera, ao falar dos últimos 30 anos que datam o ensino no Brasil, período pós-constituinte, que os ideários à esquerda política são dominantes em diversos campos para tentar justificar o apoio institucional ao ensino "doutrinador de ideologias de esquerda” (ESCOLA SEM PARTIDO, 2018b), sendo que um dos valores da Constituição de 1988 é a consolidação de um regime democrático no país, o que permite a pluralidade de ideias e concepçóes para a construção de uma sociedade brasileira mais igualitária.

Por último, é notório que, no discurso, há contrariedade argumentativa. Inicialmente é como se esta publicação expressasse a defesa pela imparcialidade no ensino, no entanto, no decorrer da argumentação, o que se tem é defesa de um único ideário/“ideologia” por meio de um argumento falacioso, o de dominação da esquerda política no Brasil ao longo dos últimos 30 anos, acrescido ao apoio ao candidato (até então, e atual presidente) Jair Bolsonaro.

A terceira e última análise é referente ao compartilhamento de outra notícia pela página ESP no Facebook, coletada para análise no dia 01 de novembro de 2018; o título é "Professor festeja vitória de Bolsonaro com churrasco em sala de aula”, do jornal digital "Metrópole”. A publicação continha mais de 4,3 mil reações (incluem-se curtidas), 2,03 mil compartilhamentos e 500 comentários, foram destacados dois deles, realizados por dois usuários da rede social distintos, não identificados: (I) "Sou eleitor do Bolsonaro, escola sem partido É 
SEM PARTIDO NENHUM...”; (II) “Em sala de aula tá errado. Poderia ter convidado os alunos para um outro local, até na rua, se fosse o caso!”.

Os autores dos comentários e apoiadores do ESP partem do pressuposto de que o movimento é neutro, não podendo ter manifestações como a comemoração mencionada em ambiente escolar. No entanto, é possível notar que há uma "falsa” neutralidade, já que, em muitos momentos, como na análise do segundo discurso, há um apoio declarado a uma figura política específica e ataques falaciosos aos ideários políticos mais aproximados à esquerda, o que ocorre em outras manifestaçôes públicas do movimento, expressando, na realidade, a ausência de neutralidade. Ao fazer críticas pontuais, como no caso desta publicação, com a crítica à comemoração de um professor, há justamente a intenção de se transmitir neutralidade, porém, o movimento cai em contradição pelo fato de que a maioria das críticas apresentadas ataca apenas um tipo de "doutrinação”, a da esquerda. Quando a página do ESP condena um churrasco comemorativo eleitoral dentro da sala de aula, não condena uma prática de ensino ou educativa, mas aponta um erro pedagógico grave, ao contrário do que acontece quando práticas de ensino, como o uso de determinadas bibliografias são distorcidas pelo movimento com intuito de definir o que é doutrinação.

Com estas considerações, os discursos dos comentários mencionados são baseados em uma falsa premissa, a de neutralidade, fazendo com que tais argumentos sejam invalidados como expressão de verdade. Além de que, mesmo se a premissa fosse verdadeira, assumindo que "escola sem partido é sem partido nenhum", se apresentaria como problemática pois, como visto nos conceitos de Sérgio Buarque de Holanda (1995), mencionados na seção 2.1 deste trabalho, é desejável que crianças e adolescentes tenham senso crítico incentivado ao invés da censura.

Buscou-se demonstrar que, apesar de ter sido fundado em 2004, o Escola Sem Partido ganhou força e visibilidade especialmente nos últimos quatro anos com a elaboração de projetos de lei cujas diretrizes entram em concordância com as ideias defendidas pelo movimento, utilizando de modo intensivo as redes sociais. Uma das principais motivações para o ganho de influência do movimento na sociedade brasileira é a ascensão de grupos conservadores no cenário nacional e mundial e um discurso pautado na existência de um "perigo" que 
"corrompe" os alunos. O uso de chavões como ideologia, gênero, ditadura e outros mobilizam a atenção e o engajamento contínuo dos seguidores.

A influência religiosa e o argumento de defesa da família, traços fundamentais na concepção tradicional e conservadora, entram como fatores importantes no fortalecimento do ESP no cotidiano e na prática política, ao mesmo tempo em que teóricos demonstram conceitualmente que tais influências no âmbito do ensino delineiam grandes problemáticas, dificilmente contornadas, se consolidadas.

Pontua-se, por fim, que no período pós-eleitoral, em que políticos que apoiam o movimento e vice-versa foram eleitos — não excluindo os gestores públicos que já realizavam o apoio antes mesmo do último período eleitoral - a possibilidade de aprovação dos projetos de lei mencionados ou de novos textos referentes a tal assunto é mais concreta. Porém, mesmo com este indício iminente, que descaracterizaria valores constitucionalmente garantidos, como a laicização do Estado e, por conseguinte, dentro das escolas públicas e a liberdade de ensino presente na Lei de Diretrizes e Bases de 1996, a situação não é irreversível ao se considerar a mobilização de forças sociais opostas. 


\section{REFERÊNCIAS BIBLIOGRÁFICAS}

ARENDT, H. A condição bumana. 10. ed. São Paulo: Editora Forense - Universitária. 2007.

ARENDT, H. Entre o passado e o futuro. 2. ed. Tradução Mauro W. Barbosa de Almeida. São Paulo: Editora Perspectiva, 2011.

BRASIL. [Constituição (1988)]. Constituição da República Federativa do Brasil. Brasília, DF: Senado Federal, 1988.

BOTELHO, A.; FERREIRA, G. N. Revendo o pensamento conservador. In: FERREIRA, G. N. e BOTELHO, A. (Org). Revisão do Pensamento Conservador: ideias e políticas no Brasil. São Paulo: Hucitec / Fapesp, 2010.

CIAVATTA, M. Resistindo aos dogmas do autoritarismo. In: FRIGOTTO, Gaudêncio (Org.). Escola "Sem" Partido: Esfinge que ameaça a educação e a sociedade brasileira. Rio de Janeiro: Lab. de Políticas Públicas da Universidade do Estado do R. de Janeiro, 2017.

CHAUÍ, M. O que é ideologia. São Paulo: Editora Brasiliense. 2017.

DE MORAES, S. P. Atentado à democratização da educação: A falácia do projeto escola sem partido. Revista Educação-UNG-Ser, v. 13, n. 1, p. 162-177, 2018.

ESCOLA SEM PARTIDO. Escola Sem Partido (página oficial no Facebook). 2018b. Disponível em: https://www.facebook.com/escolasempartidooficial/. Acesso em: 04 nov. 2018.

ESCOLA SEM PARTIDO. Quem Somos. 2018a. Disponível em: http://www.escolasempartido.org/sobre/quem-somos. Acesso em: 14 out. 2018.

ESCOLA SEM PARTIDO. Entrevista de Miguel Nagib à revista Profissão Mestre. 2018. Disponível em: http://escolasempartido.org/midia-categoria/395-entrevista-de-miguel-nagib-arevista-profissao-mestre. Acesso em: 14 out. 2018. 
FISCHER, R. M. B. Foucault e a análise do discurso em educação. Cadernos de Pesquisa. Rio de Janeiro, n. 114, p.197-223, 2001.

FOUCAULT, M. et al. Verdade e poder. Microfísica do poder, v. 23, p. 01-14, 1979.

FOUCAULT, M. A Arqueologia do saber. Rio de Janeiro: Forense, 1986.

GONZAGA, A. C. M;; DO COUTO, D. R. T. A DICOTOMIA PÚBLICO/PRIVADO EM HANNAH ARENDT E JÜRGEN HABERMAS. Complexitas-Revista de Filosofia Temática, v. 2, n. 2, p. 18-33, 2019.

HABERMAS, J. Mudança Estrutural da Esfera Pública: Investigação quanto a uma categoria da sociedade burguesa. Rio de Janeiro: Tempo Brasileiro, 1984.

HOLANDA, S. B de . O homem cordial. São Paulo: Editora Companhia das Letras 1995.

IGLESIAS, T. C. Conceitos de Público e Privado: Um olhar sob a luz de Habermas, Freyree, Holanda. Revista Contrapontos, v. 19, n. 1, p. 02-15, 2019.

MACEDO, E. As demandas conservadoras do movimento escola sem partido e a base nacional curricular comum. Educação E̊ Sociedade, v. 38, n. 139, p. 507-524, 2017.

MIGUEL, L. F. Da “doutrinação marxista” à “ideologia de gênero" - Escola Sem Partido e as leis da mordaça no parlamento brasileiro. Revista Direito e Práxis, v. 7, n. 15, p.590-621, 2016.

O GLOBO (Brasil). Colégio Santo Agostinho, do Rio, suspende uso de livro considerado 'comunista' por grupo de pais. 2018. Disponível em: https://oglobo.globo.com/sociedade/colegiosanto-agostinho-do-rio-suspende-uso-de-livro-considerado-comunista-por-grupo-de-pais23122273. Acesso em: 18 out. 2018.

ORLANDI, E. P. Análise de discurso: princípios e procedimentos. Campinas, São Paulo: Pontes, [1990], 2005. 
O Movimento Escola Sem Partido: ascensão e discurso

PENNA, F. A. O Estado sem Partido como chave de leitura do fenômeno educacional. In: FRIGOTTO, G. (Org.). Escola “Sem” Partido: Esfinge que ameaça a educação e a sociedade brasileira. Rio de Janeiro: Laboratório de Políticas Públicas da Universidade do Estado do Rio de Janeiro, 2017.

PORTELLI, H. Gramsci e o bloco histórico. Rio de Janeiro: Paz e Terra, 1977.

RODRIGUES, A. A. C. O conceito de hegemonia: de Gramsci a Laclau e Mouffe. Lua nova, n. 80, p.71-96, 2010.

SAVIANI, D. História das ideias pedagógicas no Brasil. Campinas, São Paulo: Autores Associados, 2010. 